\title{
"How It's Done": The Role of Mentoring and Advice in Preparing the Next Generation of Historically Black College and University Presidents
}

\author{
Felecia Commodore ${ }^{1}$, Sydney Freeman, Jr. ${ }^{2}$, Marybeth Gasman ${ }^{3, *}$ and Courtney M. Carter ${ }^{4}$ \\ 1 College of Education, Old Dominion University, 218 Education Building, Norfolk, VA 23529, USA; \\ fcommodo@odu.edu \\ 2 College of Education, University of Idaho, 875 Perimeter Drive, Moscow, ID 83844, USA; \\ sfreemanjr@uidaho.edu \\ 3 Graduate School of Education, University of Pennsylvania, 3819 Chestnut Street, St. Leonard's Court, \\ Suite 140, Philadelphia, PA 19104, USA \\ 4 Department of Sociology, 456 Hardy Road, Mississippi State University, Mississippi State, MS 39762, USA; \\ ccarter@soc.msstate.edu \\ * Correspondence: mgasman@upenn.edu; Tel.: +1-215-573-3990
}

Academic Editor: Jess L. Gregory

Received: 2 May 2016; Accepted: 14 June 2016; Published: 21 June 2016

\begin{abstract}
The college and university presidency is one of the most coveted positions in academe. Due to the projected retirements of current Historically Black College and University (HBCU) presidents, the researchers interviewed 21 current presidents, institutional board members, and presidential search firm personnel to explore what current HBCU leadership identifies as important mentoring/mentee practices, mentoring/mentee opportunities, and professional advice for HBCU presidential aspirants to consider. The findings, based on the coding and analysis of semi-structured qualitative interviews, revealed that self-awareness, focusing on the essential aspects of the job and not merely the perks, openness to being mentored and willingness to shadow a successful leader, experience in serving in various administrative capacities, participating in professional leadership development activities, earning of a terminal degree, displaying humility, understanding academic politics, and learning how to present oneself as an executive is important in the preparation of a leader of an HBCU.
\end{abstract}

Keywords: leadership; mentoring; HBCU

\section{Introduction}

Institutional leadership is a topic of interest for various higher education stakeholders. Donors, policy-makers, college administrators, students, alumni, and many other constituencies are now facilitating discussions around the selection and performance of college and university presidents. However, within the landscape of higher education, Historically Black Colleges and Universities (HBCU) have experienced challenges in the recruitment and retention of presidents [1]. One sector that has been experiencing these challenges is Historically Black Colleges and Universities (HBCU). High presidential turnover and a growing number of aging presidents matched with shrinking funding and resources have HBCU stakeholders concerned regarding the presidential pipeline for this institutional type. Furthermore, when considering that a large percentage of non-white college presidents are currently leading Minority-Serving Institutions (MSIs), being able to identify and fortify the HBCU presidential pipeline proves important for the diversity of college and university presidents. As HBCUs move forward in achieving and maintaining institutional effectiveness and sustainability, 
being able to not only identify future presidents but also to mentor and properly prepare them to lead in these unique contexts is crucial.

In this article, through semi-structured, qualitative interviews, we explore what current HBCU leadership identifies as important mentoring/mentee practices, mentoring/mentee opportunities, and professional advice for $\mathrm{HBCU}$ presidential aspirants to consider. We explore existing literature regarding presidential mentoring, presidential pipelines, and the diversity of college presidents. Then, we analyze data collected from participants regarding preparation for the HBCU presidency. Lastly, we provide implications and recommendations derived from our findings. Through this study we build on the ongoing conversation about the role of mentoring in effective HBCU leadership.

\section{Literature Review}

\subsection{Mentoring}

When attempting to create pipelines to institutional leadership and groom faculty, mentoring is an element that plays an important role. Through mentoring, mentees learn the knowledge necessary to make decisions, form relationships, commit to tasks, and make judgments in which they can trust [1]. "Mentoring provides support as faculty members make the transition into administrative roles, such as department chairpersons, associate deans, or deans" [1] (p. 35). Umpstead et al. note that without receiving training in certain skill sets, the transition for faculty members can be difficult, as successful administrators often need skills that are different from those required to be successful faculty. Umpstead and colleagues also point out that "early mid-career mentoring is particularly important because tenured professors have typically established their competence in their profession and developed their academic identity" [1] (p. 36). This is important to note as a majority of college presidents have served as faculty members at one point during their careers. There are certain types of knowledge that institutional leaders felt are important to acquire to be successful. Mentoring is one of the ways aspirants can acquire this knowledge [2]. Although getting a doctoral degree can be helpful, doctoral programs often lack the developing skills and knowledge that presidents, particularly HBCU presidents, need to be successful. These areas include fundraising, assessment, and accountability of student learning [2]. Mentoring can help fill in gaps in the theoretical and practical knowledge that is needed to succeed [2].

One of the ways that the higher education community can ensure that mentoring for the next generation of college presidents occurs is through the establishment of organized mentoring programs. Mentoring programs can assist in building both competency and confidence in mentees [1]. Mentoring programs include association-sponsored programs, organizational programs, programs for targeted groups, and within-institution programs. Reille and Kezar studied a group of mentoring programs at community colleges and found that organizational strategy was a strong focus [3]. Mentoring programs can also aid mentees in addressing issues of professionalism as well as self-knowledge, emotional intelligence, ethics and integrity, courage, perseverance, and servant leadership [3]. Elements found in "grow your own" mentoring programs at community colleges include managing vision and purpose, dealing with ambiguity and strategic agility, vision, creativity, and organizational analysis, systematic planning, deliberative decision-making, crisis and conflict management, visionary college leadership, the administrator as an agent of change, changing colleges for changing students, envisioning the college of the future, and fostering a culture of continuous institutional improvement [3].

However, the desire for institutions to institutionalize mentoring and develop within-institution mentoring programs can be difficult due to the challenges in the ability to secure mentors [3,4]. Mentors can include professional peers within and outside higher education institutions [4]. For this reason, it is suggested that within-institution programs consider finding mentors outside of the institution. Regardless of whether mentors are external or internal to an institution, the experience mentees have is important. Although there is existing literature regarding the mentoring of faculty and students of color, little attention has been given to the mentoring of academic and administrative leaders of 
color [4]. Due to the fact that many HBCU presidents are people of color, it is imperative to understand the mentoring experiences for those aspiring to be college presidents, through racial, ethnic, and gendered lenses.

\subsection{The HBCU Presidency and Mentoring}

The study of the HBCU presidency has historically been neglected in higher education literature. The majority of scholarship on the topic of the HBCU presidency has developed in the form of biographies. This literature presents leaders of these institutions as "power hungry, dictatorial, and incompetent" [5] (p. 4). Until the last 20 years, the HBCU presidency had not been researched using generally accepted rigorous research methods [5,6]. Outside of biographies, much of the literature did not provide the full context regarding the challenges that HBCU presidents have and continue to contend with to ensure the success of these important institutions [7]. Many HBCUs were born out of segregated southern culture. Therefore, these institutions had to contend with the humiliation of segregation and discrimination. Although current U.S. laws forbid discrimination based on race, the residual effects are still seen and felt today. Years of neglect, because of underfunding by states, have left many of these institutions vulnerable. Often times, for example, consider the current legal case in the state of Maryland, HBCU leaders and/or their advocates have had to sue their states to help remedy these past injustices.

Although HBCU presidents have been characterized as dictatorial and power hungry, some scholars contend that their strong leadership approach may have been the only way to ensure their institutions' survival [8,9]. Much has changed since the mid-to-late 1800s in the U.S. when many of the first HBCUs were established. Innovations such as the role of technology have changed the landscape of higher education. However, the role of the HBCU president as the chief representative of his or her institution has not changed. The main responsibilities of higher education presidents are fundraising, budgeting, community relations, and strategic planning [10]. Researchers have found that HBCU presidents have come from a diversity of backgrounds and have engaged in a plethora of experiences before securing these posts [5]. The majority of presidents have gained their leadership skills within the academy, whereas others have developed their skills in other areas of the public and private sectors [5].

Developing the skills and characteristics to be an effective president does not happen solely because of a person's academic training and experiences [5]. Research has shown that mentoring is an important aspect of the leadership development of college and university presidents. In various studies specifically those reviewing the HBCU presidency, the presidential participants acknowledged that mentoring was critical to their successes $[5,11,12]$. Moreover, there are expectations that current leaders serve as mentors and prepare other presidential aspirants for such opportunities.

\subsection{Diversity and the College Presidency}

The U.S. population is becoming increasingly racially diverse. In fact, by 2020 it is projected that a majority of the country's population will be made up of people of color. This demographic shift will ultimately affect the college student population-it too will become more racially diverse. In fact, the effects of this shift can already be seen as many college campuses, particularly public institutions, are beginning to see their campus diversity increase. However, as student diversity increases, the same increase in diversity is not present in faculty and administration. Specifically, this increase in diversity is not reflected in the college presidency.

In 2011, $12.8 \%$ of college presidents were people of color. When Minority-Serving Institutions (MSIs) were excluded, that number dropped, moving from $12 \%$ to $9 \%$ [13]. When focusing on gender, $26.4 \%$ of college presidents were women, most of which were found at public institutions [13]. The question arises, why are people of color and women not reaching the college presidency in greater number? The issue lies in the pipeline to the presidency. Twenty-four percent of college presidents reported holding the office of president as their position held most recently before becoming president 
of their current institution. Also, $68.9 \%$ identified as at one time holding a faculty position prior to the presidency. As MSIs, and HBCUs in particular, have more diverse faculty in general and more Black faculty members specifically, HBCUs play a major role in Black men and women attaining the college presidency. To go a step further, because HBCUs contribute such a large percentage of Black presidents to the larger college presidential landscape, to ensure that strong, prepared leaders are reaching these posts at HBCUs, more must be understood about the HBCU presidency, how aspirants are being prepared, and if they are successful.

\section{Theoretical Framework}

Bozeman and Feeney's Theory of Mentoring pays particularly close attention to the transmittal of knowledge. More specifically, the authors compare three processes for transmitting work-related knowledge within the mentoring relationship.

The three processes of knowledge transmittal are formal training, socialization, and mentoring. Work-related information is transmitted through formal training, socialization, and mentoring. Although you can achieve work-related knowledge through formal education programs and work experience, mentoring provides unique access. Mentoring serves the needs of both participants voluntarily, and is work-related and from a self-interested perspective. Therefore, the transmittal of knowledge is more likely to be useful and applicable to the individuals involved and their respective contexts, such as the HBCU sector.

Bozeman and Feeney also use this transmittal of knowledge as an indicator to the end of the mentoring relationship, "(at least in that domain, though it may continue in another)" [14] (p. 733). This includes the transmittal of social capital—networks and ties—from the mentor to the protégé.

\section{Sponsoring}

Hand in hand with the practice of mentoring is that of sponsorship. Sponsorship differs from mentorship in that sponsors go the extra step of actually advocating for the mentee [4]. Sponsoring allows the mentor to serve as an entry point within a specific professional community with which the mentor has a notable amount of social capital. In the area of preparing and equipping the next generation of $\mathrm{HBCU}$ presidents, it proves important to gain a deeper understanding of the role and impact of mentoring and sponsorship in properly accessing and navigating HBCU presidential pipelines. Although workforce and leadership development literature discuss the role of mentoring, understanding how mentoring relationships occur and are executed within specific organizational cultures, communities, and contexts requires further exploration. Insight into mentoring and access to advice contributes to the successes of both those aspiring to the HBCU presidency and those in the position to select presidential candidates. As the HBCU sector considers how to fortify the presidential pipeline, knowing more about the role of mentoring, sponsorship, and the availability of sage advice from sector insiders proves essential.

\section{Methods}

This study analyzed semi-structured, qualitative interviews to achieve an in-depth understanding of the perspectives of current presidents, search consultants, and board members affiliated with HBCUs regarding the future of the Black college presidency. Analyzing qualitative interviews aids in probing beneath the surface and gaining rich context regarding the current and future state of the HBCU presidency [15].

These groups of individuals were chosen as the participant population because they were each integral stakeholders in the hiring process of new presidential leadership at Black colleges and have participated in searches in some capacity in the past. To identify an adequate sample, we reviewed the U.S. Department of Education's White House Initiative on HBCUs listing of 105 member colleges and universities. From there, we contacted the offices of the presidents of these institutions and requested their participation in the study along with asking them to provide names and contact information 
for board members and search consultants that would be willing to serve as participants. Then each president was sent an email and called by telephone to invite them to participate in the study. Once the initial contact was made, a follow-up email was sent and a call by telephone was made to confirm the time of the interview with each participant.

Twenty-one individuals participated in the study. The participants included 16 sitting presidents, three board members, and two presidential search consultants. All interviews were conducted by phone. These open-ended interviews lasted between 30-60 min. Audio equipment was used for data collection purposes. An interview script was used throughout the interview process. Copious notes were taken along with an audio recording of each interview. Summary notes were recorded directly following each interview. The presidents' reactions and comments and the interviewers' preliminary thoughts on the emerging themes were recorded in the log as subscribed to by Miles and Huberman [16] and Gasman and Anderson-Thompkins [17].

Following the initial interviews, we reviewed the transcripts and recordings and constructed follow-up interview questions tailored to the individual presidents. These follow-up questions were used for the purposes of member checking and data validation. Follow-up questions were distributed via email. Member checking was used to determine the trustworthiness of the data. By using member checking, the presidents were able to review the notation from the previous interview to ensure that they correctly reflected the presidents' feelings and responses [18]. After coding the data using NVIVO, we engaged in what Patton describes as analyst triangulation. This form of triangulation allows for the use of multiple (two or more) analysts to evaluate the study findings [19].

\section{Limitations}

Qualitative research can provide rich data and a narrative context for data including experiences, feelings, opinions, and knowledge [19]. However, qualitative research has its limitations. One limitation is that qualitative data is not generalizable. For this study, the small sample size restricts the widespread application of results to all Black college presidents. Additionally, although we attempted to include as many women participants as possible, only two participants identified as women (one president and one search consultant). This small representation of women within the participants creates a challenge in capturing data reflecting gendered experiences. Gaining access into HBCU leadership communities and circles has been a challenge for various researchers. This challenge occurs partly due to issues of the historical misuse and misrepresentation of data collected through HBCU research. This history may have created a lack of trust in outside researchers, their collection methods, and uses of data [5]. As outside researchers, the access granted to these circles was limited.

\section{Findings and Discussion}

\subsection{The Importance of Mentoring}

All study participants highlighted the importance of mentoring in the success of aspiring presidents, although they differed in experiences with formal and informal mentoring practices. "I think we develop them (skills) by having mentors, people who we either admire, work with, consult with, who can help us develop those skills," said one president. Another president stated, "I think what you would need to do is find someone to mentor you, find someone on an HBCU level who's respected in the HBCU community that you may know or someone else may know, who can mentor you." Participants felt these mentoring relationships were vital. One president responded that aspirants “... have to develop several mentoring relationships with individuals on a regular basis, on a pretty consistent basis, and give them feedback about where they are and help them develop as leaders, who can invite them to their campus." Literature supports the importance of identifying a mentor, but also highlights the challenges of securing a mentor, particularly for persons of color [4]. Furthermore, the findings of Chang and colleagues support the notion of developing several mentoring relationships, explaining how traditional definitions of mentoring, one-on-one mentoring, do not always fit with the 
experiences of the mentees. These mentoring relationships included developmental relationships as well as peer professionals [4].

A key aspect of mentoring is the idea of shadowing. A number of mentoring programs include an element of shadowing [3]. Likewise, shadowing a president was often mentioned by participants as important preparation for the HBCU presidency. Six of the sitting presidents interviewed mentioned that they really had no idea what it was a president did until they actually saw them do it. By working closely with a president many participants shared how the mentoring presidents pointed out skill sets that mentees needed to develop. Also, in shadowing an HBCU president many of the participants were able to see the unique challenges and the particular ways one must navigate within the HBCU context specifically. For those aspirants who may not have had prior experience working within the HBCU context, shadowing also provides insight into a culture with which they will need to be intimately familiar in order to be successful.

In the case of higher education leadership, opportunities for mentees to participate in shadowing can be challenging due to the time constraints of accessible mentors [3]. Therefore, the ability to properly groom presidential aspirants is also challenging. There is no discussion pertaining to whether or not this is more or less of a challenge in the HBCU sector. However, HBCUs have a unique institutional context and culture in which they operate. One who desires to lead an HBCU can only benefit from early exposure to the HBCU culture and community. Whether or not one has experience with HBCUs, the practice of shadowing a current HBCU president is beneficial. Not only did participants share that they learned a lot about the day-to-day job of an HBCU president through shadowing, but also they learned much about themselves.

Although all participants agreed that mentoring was an important part of the path to the presidency, there was no consensus as to the way in which that mentoring should or could occur. This reflects Bozeman and Feeney's assertion that, currently, defining mentoring is difficult as it is often conflated with adjacent concepts [14]. The conflation of concepts also creates difficulty in identifying the best manner in which to mentor. One president summed up this sentiment by saying, "Mentoring happens in a lot of different ways." Both formal and informal mentoring opportunities were championed. Three participants felt a singular leader should mentor aspirants. For example, one president felt that a one-on-one relationship allowed the mentee to observe and learn skills in an up-close and personal setting. "At least for me the experience that was the most helpful was just watching up close how it's done and seeing the strengths and weaknesses of that person and taking that information and using that which you feel you want to and disregarding those things which you think are inappropriate for you," the participant shared. Another president stated, "You have to work around someone who is humble, so I think you have to humble yourself in order to lead any of our colleges, and he would have to work around someone, be around someone, who can teach you exactly how to do that." One president expounded on the idea of gleaning skills and coaching that can be received from an individual mentor.

They (skills) will be acquired also from pairing yourself with someone who is more skilled in a particular area than you and calling on them to help mentor you or to help be a sounding board or person that you can call on for particular skill sets that you may not have acquired and may not even have the need to acquire ... they stated.

However, the president went on to say that,

... So it's not that you're going to have to walk around with all of the skill sets within your person. It may be that you are smart enough to line up a cadre of folks that you can bounce things off of who are specialists in those particular areas, who can keep you abreast of what is actually coming down the pipe or what is subject to be going on based on the trend data that is out there.

This latter sentiment is what many of our other participants echoed. Six of the 22 participants felt that it was important to have a team of mentors hailing from various positions in academia at majority 
institutions and at HBCUs, in particular. Explaining that those striving towards the presidency needed to learn a variety of skills, one president pointed out that having several mentors aided this process. "Some people have one mentor or two mentors for everything. Different people have different sets of experiences and expertise and no one is an expert in every area. And I like to call them my personal board of advisors. I have different mentors for different issues," the participant shared. Another president expressed that having several mentors allowed for a wealth of feedback. "The second thing is they have to develop several mentoring relationships with individuals on a regular basis, on a pretty consistent basis, and give them feedback about where they are and help them develop as leaders, who can invite them to their campus." Traditional versions of mentoring can be incongruent with the needs of those needing mentoring. Although "heavy-handed" mentoring (traditional mentoring with long-term relationships) has its benefits, benefits can also be derived from "light-handed" mentoring (developmental relationships with multiple peers) [14] (p. 378). Regardless of how mentoring is accessed or exercised, each participant expressed, via sharing of their own personal stories, the magnitude of learning that occurs through the mentoring process.

Formal mentoring programs were suggested for presidential hopefuls. Programs mentioned were the ACE Spectrum program and the ACE Fellows program. The ACE Spectrum Executive Leadership program is a six-month program targeted to underrepresented groups designed to further diversify leadership in U.S. higher education institutions. Those who participate in the program: prepare for the presidential search process, engage in generative dialogue about the nuances of the presidential search process through the lens of race and gender, interact with presidential facilitators from diverse backgrounds and institutions for guidance in preparing for the search process and the presidency, build a network of peers who share common concerns, experiences and career aspirations, engage in small group and panel discussions on major issues that shape the landscape of U.S. higher education, among other activities [13].

The ACE Fellows program has more than 1800 vice presidents, deans, department chairs, faculty, and other emerging leaders who have participated. The ACE Fellows program helps ensure that higher education's future leaders are ready to take on real-world challenges and serve the capacity-building needs of their institutions. The fellows observe and participate in key meetings and events, take on special projects and assignments while under the mentorship of a team of experienced campus or system leaders, participate in three multi-day seminars, engage in team-based case studies, visit other campuses, attend national meetings, develop a network of higher education leaders across the U.S. and abroad, [13]. Most presidents mentioned the ACE Spectrum and ACE Fellows programs specifically. It is not clear if the reasoning behind the mention of these specific programs by participants is because the participants found these programs to be superior, or because these are programs target HBCU and/or African American presidential aspirants.

The presidents participating mentioned their own personal involvement with the ACE Spectrum and ACE Fellows programs as either mentors or former mentees. These presidents have also been tapped to be mentors for other groups focusing on underrepresented groups, such as women, in the college presidency. Given the unique context of HBCUs it may be of interest to have formal mentoring programs that speak to the challenges and scenarios that will be commonly found by those reaching the presidential seat. Formal mentoring programs, especially those on the institutional level, provide training that is tailored specifically to the context in which the future leaders will find themselves [3]. Not only should higher education associations consider developing these programs, but for programs that are targeted towards those most likely to be candidates for the HBCU presidency, such as African Americans, associations should take the time to include information to enhance the understanding of the HBCU sector. Targeting African-American leaders for mentoring programs can aid in dismantling the "structures and culture of higher education (playing) a powerful role in both facilitating and inhibiting the development of leaders of color through sanctioned and limited opportunities of mentoring" [4] (p. 383). 
Informal mentoring seemed to be the more popular form of mentoring participated in and practiced by participants. One president noted, "Sometimes mentoring doesn't have to be a formal relationship, but it means you have to be observant with people who are doing things that you aspire to do." Presidents touted that it was through mentoring that both practical and theoretical information is shared. "Maybe someone can go to a seminar and get it, I don't know, or read about it, but there's nothing like being in an environment where you can observe someone who is exhibiting those traits and characteristics that are necessary to be successful as a president," mentioned a president. This information includes a range of topics from what skills are important to acquire to making sure to wear the school colors when interviewing for an HBCU presidency. Next to learning on the job, mentoring is the best means to learn how HBCUs work, how to navigate the HBCU presidency, and how to communicate and interact with the various $\mathrm{HBCU}$ constituents. Some argue that mentoring does not have to be interpersonal to occur. In fact, six of the 22 participants mentioned that you can learn much about the path to the presidency and what it takes to reach the HBCU presidency simply from observing, even if from afar.

Other presidents felt that traditional, one-on-one mentoring was still the best way to learn the most and gain the best information about what it means and what it takes to be an HBCU president. Developing a relationship with an HBCU president also arose as an important theme. Sitting HBCU presidents mentioned their own presidential mentors and how instrumental these mentors were in teaching them the skills needed to be a successful president. In addition, many of these presidential mentors were able to identify the potential the participants held that would make them good picks for the HBCU presidency. One president expressed this sentiment,

Without the right mentors there is no way I would sit in this chair today. Without the right mentor I was never going to get a doctorate. That was never in my plan. Without the right mentor I would not have moved to different institutions to get varied experiences. It just wasn't in my lens and I know for a fact without the right mentors I would never have had this opportunity.

Being able to help move individuals from presidential hopefuls to actual sitting presidents is the ultimate goal of mentoring. One president stated, "I have been mentoring young women for a while. In fact, two of my mentees are now presidents, so I feel good about that." Therefore, these mentoring relationships were not important simply because those who want to be presidents can learn from sitting presidents, but also because they provide an opportunity for sitting presidents to identify up-and-coming talent and in turn aid and increase access to the HBCU presidential pipeline.

\subsection{Advice for Aspiring Presidents}

Through our interviews, several emerging themes surfaced. Participants strongly felt that there were key bits of information that HBCU presidential hopefuls needed to be aware. Although board members said things such as "... I don't think that there is necessarily any (one) path to getting there," there was much advice shared regarding the path to the HBCU president's seat. This advice will help presidential hopefuls achieve success as they embark upon their path to the HBCU presidency and aid in presidential hopefuls being effective once they attain the presidency.

Aspirants were encouraged to truly know who they were as a person and as a leader. Self-awareness is often an element of the formal training process of transmitting work-related knowledge [14]. Participants felt that persons aspiring to the presidency must be keenly aware of their strengths and weaknesses in order to be an effective leader. Aspirants must also understand their personality and leadership style. One president expressed this sentiment by saying, "Get to know yourself. You've got many people who don't know who they are." Understanding these things can assist aspirants in finding opportunities to exercise their strengths as well as opportunities to become stronger where there are weaknesses. It is not in the position of president where candidates should discover these traits. Although the presidency will undoubtedly test and develop some of these traits, 
persons with a strong and critical awareness of self will fare better when seeking the office as well as once occupying it.

Many participants felt like persons pursuing the presidency often were motivated or distracted by unimportant aspects of the job. Statements from presidents included:

... You need to look in the mirror and you need to really, really answer the following question: Why? And you need to be honest with yourself. And if you don't know why, then you don't want to be an HBCU president, and you don't do it for the glory. You don't do it for the money. You don't do it for the prestige. You have to do it because you really, really want to make a difference in the lives of young people and help an institution progress.

One president provided the following advice for those intrigued with the HBCU presidency,

It's not about prestige. If you're thinking that, then you need to think further. It's not about the house. It's not about the car. And if that's what you're thinking about this, in terms of the perks, for the most part, I'm not ready to have a conversation with you. You're just a waste of my time. But if you are thinking about it in terms of focus on students, the transformation of students, then I think you need to make sure that you're getting the kinds of experience that will enable you to have the kinds of skills in these four or five arenas: in the political arena, in the academic arena, in the fundraising arena, in the entrepreneurial arena, and then you need a global and international perspective on all of that.

Having mentors and shadowing presidents offered participants an honest and true perspective on the presidency. These experiences also offered opportunities that pushed the participants to learn skills and work on areas in which they were weak. The vantage point of a sitting HBCU president allows aspirants to gain insight and guidance from someone who knows the job better than any other. This finding supports Bozeman and Feeney's assertion that the mentoring process of work-related knowledge transmission allows for the mentee to learn the necessary knowledge, but in a way that is from the "self-interested perspective of the two parties" [14] (p. 735). Along with shadowing a president, building relationships and identifying a mentor who is respected in the HBCU community were also deemed important.

Although the literature often positions mentoring as a whole different process of knowledge transmission [14], participants found the two processes often intertwined. Participants did not merely encourage gaining experience but gaining a variety of experiences. Five of the 22 participants stressed the necessity to work at many different institutions in order to prepare for the HBCU presidency. Even working in different leadership capacities within a single institution was encouraged as a variety of experiences aids in learning various school structures and operations that will serve aspirants well if they attain an HBCU presidency. One president stated, "I think having some kind of administrative position, whether it's a department head, whether it's in charge of a program, again just being in some position where you do evaluations, where you do promotions, where you do all the ways and things will then prepare someone to do it at even a larger level." Having a variety of experiences can aid aspirants in accessing new opportunities for exchanges and collaboration [1]. A variety of experiences also opens up opportunities for mentees to build networks and gain insight regarding the roles and responsibilities upper-level administrators and presidents face. It was a popular sentiment that institutional context was of less importance than types of administrative positions persons held and executed. In acquiring these varied experiences, presidential hopefuls will be able to easily adapt to new environments and be able to identify similar or dissimilar characteristics to places they have previously worked.

While working in these new environments, it was also advised to really learn and understand the role of the faculty and the role of the board at an institution. This socialization process enables aspirants to gain a necessary knowledge and understanding of not only group norms but also the cultural norms of higher education [14]. Fifty percent of participants felt the best way to understand 
and be able to relate to faculty was to have been faculty or to have an extensive and strong academic background. "When you're the academic leader, the main people who you're going to be interacting with are faculty, and I think having the respect of faculty, having been successful as faculty, even though I mentioned there are instances of people coming from other disciplines, I actually think that is the most important quality," one president shared. Learning early the role of the faculty and the board in an institution's governance practices, as well as being able to garner faculty and board respect, puts presidential hopefuls ahead of the curve.

Experience is not limited to just the occupational professions. Although participants echoed that nothing could replace on-the-job experience, formal education plays an important role. Attaining a terminal degree, preferably a Ph.D., was strongly suggested. One president stated, "First I would say if you don't have the terminal degree that is something you have to have bar none ..." Another president shared that "If you want to be a president, you're still probably going to need a Ph.D." Participants also felt that those who had taken the extra step of attaining a Ph.D., specifically in higher education, deeply understood how higher education works, how their institutions fit in the grander higher education landscape, and various ways in which their schools could do what they do even better and even more effectively. It is to the candidates' advantage to know both theory and the application of theory.

Fundraising was a specific area in which sitting presidents felt it imperative for those seeking the presidency to possess experience. This perspective mirrors what much of the literature surrounding HBCU leadership espouses. One of the biggest challenges many HBCUs face is in the area of finances. Therefore, many institutions are looking for or are in need of a president who can not only balance a budget, but is also able to identify and successfully tap streams of income.

\subsection{The Role of Soft Skills}

Participants also stressed the role that politics, presentation, and personality play in achieving and being successful in the presidency. Regarding politics, many participants explained that being the president was not solely about the competency to do the work. One president even felt that getting to the position of president was less about skill and more about timing, stating, "You don't get to become president because you're good. It depends on being in the right place at the right time, with the right kind of board." Another president echoed similar feelings, saying, "The thing about it is it's more political than it is skill. The best person doesn't get the job most of the time. The person who gets the votes gets the job." Participants sharing the importance of being able to navigate the political aspects of attaining the HBCU presidency reinforces the importance of having a mentor who can aid in identifying and interpreting said politics. The mentoring process uniquely aids in the transfer of this knowledge [14].

According to participants, aspirants need not only desire to be presidential: aspirants must also possess or perform an aesthetic that communicates a presidential presence to stakeholders. One president shared:

You really have to practice what one is supposed to look like. I have colleagues with the desire to be basically senior presidents and extremely competent, oh my gosh, far more intellect than I could ever imagine, brilliant administrators, many of the tools and skills required. But they don't look like a president. Their attire is not presidential. You can have on a suit but it's just not a president's suit. So you have to remember when you walk into that interview room with the Board or when you walk onto that campus for your campus visit people are going to see you before they hear anything from you.

The role relationships play in being successful was frequently mentioned by participants. "I think it's about being very competent, being known as a man, a woman, of integrity, getting to know folks," shared one trustee member. A president stated, "...they need to build relationships with other people in HBCUs. I think that going to conferences, and meetings, I don't know that necessarily the topics discussed are worth a bucket of warm spit. But the relationships you make, the serious conversation 
you have over a beer with a colleague after supper that can be where the real critical stuff happens." Having relationships and understanding the HBCU context, or that "You need to understand the flavor of what an HBCU is," proved to be an important quality to possess.

Participants did give advice that did not pertain to specific skill sets but to personality and perspective. The sentiment shared was that attitude played as important of a role as aptitude. Humility was shared as advice. One president stated, "Then last but not least, keep working on yourself because presidents aren't departmentalized. The type of person you are is going to impact the type of leadership you bring to an institution." The fact that many sitting presidents uttered this as advice speaks contrary to the historical narrative of prideful, pompous HBCU presidents. It appears that most presidents view humility as a trait that assists in their success. Aspirants are encouraged to have passion and to make sure that passion generates from an authentic place. Sentiments were shared that one must choose and remain in this career because they want to make a difference in the lives of the young people attending their institutions. If this is not the case, they will undoubtedly lose their passion and their focus. Other advice given was to demonstrate excellence, demonstrate pragmatic leadership, and have flexible, broad vision. Overall, participants advised those in hope of one day reaching the HBCU presidential seat that although there is no one path to the presidency, to take and make the most of all opportunities that arise.

\section{Recommendations}

\subsection{Recommendations for Practice}

It is essential to create opportunities for mentoring. Mentorship was a clear theme among participants as it relates to becoming an HBCU president. Although both formal and informal mentor programs exist, there are far too few. Mentoring opportunities within the HBCU sector must be increased. A program that can identify $\mathrm{HBCU}$ presidential aspirants and connect them with sitting HBCU presidents would aid in increasing access to the presidential pipeline. Although informal mentoring plays an important role, more formal, financially supported programs could increase diversity in mentees. These programs would prove most beneficial if they had multi-year components or cohorts as opposed to singular occurrences.

Based on the information and advice provided by participants, these mentoring programs should provide access to traditional models of mentoring and also access to a range of mentors with a variety of skills and experiences to expose to mentees. It would be most beneficial to have mentors who are familiar with HBCU culture and shared practices, both explicit and implicit. Although mentees would benefit from mentors from various institutional types, due to some of the unique challenges of HBCUs, mentors familiar with the HBCU community would prove most beneficial in the transmittal of knowledge. These mentoring programs should also be incentivized for both mentees and mentors to participate. Time commitments for both parties create challenges concerning participation. However, if there are incentives to committing to the program, these participation challenges could be successfully navigated.

\subsubsection{Diversifying a Variety of Pipelines}

One of the pieces of advice that presented itself in the data is the need for presidential aspirants to gain a variety of experiences across an institution. This can only occur if hiring practices at higher education institutions aim to recruit, attract, and retain diverse groups. To achieve this goal, institutions must make efforts to attain both financial and psychosocial resources. There must also be a concerted effort to encourage a diverse group of internal applicants to apply for positions as well as be considered for promotions and leadership roles. Targeted recruitment in diverse pools as well as the provision of professional development opportunities for diverse groups of people aid in creating the necessary measures to ensure those seeking the HBCU presidency are well equipped while in the pipeline. 


\subsubsection{Opportunities for Professional Development}

Participants noted that there were various areas of professional development that would aid aspirants in not only reaching the HBCU presidency but also in being successful in the role. These areas included learning more about the role of faculty and the board of trustees, pursuing a terminal degree, and developing soft skills. In order to adequately prepare the HBCU presidential pipeline opportunities to satisfy these areas of professional development, current presidents can use mentoring and shadowing opportunities to introduce aspirants to interactions with board members as well as faculty. With regard to pursuing a terminal degree, institutions such as HBCUs, which are organizations prime for HBCU presidential aspirants, need to provide environments and resources to give non-faculty members the opportunity to pursue terminal degrees. Also, providing resources to aid those in the HBCU presidential pipelines in developing soft skills will prove beneficial.

\subsection{Recommendations for Research}

Mentoring and its impact have been studied in higher education, but mostly in the areas of faculty and student development. A deeper understanding of the impact of mentoring and ways in which is it is facilitated, for higher education leaders and administrators, is needed in the literature. Researchers should consider studying effective mentoring programs for future presidents, and specifically future presidents of color. To go a step further, programs that are established for future HBCU presidents and other MSIs need to be explored to see what impact they have on the success of those aspiring to the HBCU presidency. For programs that are already established, elements that are unique to the preparation of leading within the HBCU context should be uncovered. Learning what these elements are will aid in ensuring future HBCU presidents have what is necessary to be successful. Uncovering this information also aids in knowing what elements and methods are crucial in the formulation of new programs aimed at the HBCU presidential pipeline.

Much like the broader literature focused on mentoring within the higher education sector, the mentoring literature that focuses on the racial and gendered experiences and needs of mentees and mentors heavily favors faculty and students of color. There is limited literature regarding the experiences, needs, success, and challenges in the area of mentoring future higher education leaders of color, particularly future Black leaders. Although there is a small body of literature that focuses on the experiences of Black women college presidents and their journeys to the presidency, there are few studies that speak to the role of mentoring specifically. Understanding the mentoring experiences at the intersection of race and gender provides insight into the role mentoring plays or does not play in women of color accessing, succeeding, and thriving in the HBCU presidential pipeline as well as the HBCU presidency. Increased knowledge about these experiences also adds to and diversifies the definition, understanding, and application of the concept of mentoring in higher education.

\section{Conclusions}

As the country strives to reach its degree completion goals, the role and sustainability of HBCUs is critical. Being able to have seamless transitions as HBCU leadership retires will prove important in achieving said sustainability. Proper preparation along with access to knowledge, social, and cultural capital aids those aspiring to the HBCU presidency to be successful. Future studies regarding the path to the presidency as well as an increased understanding about the presidency in the unique HBCU context will aid organizations and those invested in HBCU leadership.

Mentoring is important in preparing leadership. Although the traditional methods of one-on-one mentoring, including shadowing, prove to remain important and to have an impact, for aspiring HBCU presidents, various forms of mentoring are beneficial as well. This includes having a variety of mentors and a variety of mentoring experiences. Current and past $\mathrm{HBCU}$ presidents should identify two to four individuals to mentor for the HBCU presidency. At least one of these persons should be internal to the institution for which they work. The mentees selected should also range from being 
early in their higher education careers to upper-level administrators. Faculty who have administrative promise or aspirations should also be considered. This more traditional form of one-on-one mentoring should include regularly scheduled communication, shadowing opportunities, short- and long-term goals for the mentoring relationship, timelines for said goals, and ways to measure progress.

Mentoring can be productive but more formal mentoring programs must be established. To be more specific, formal mentoring programs that speak to the unique culture and context of HBCU campuses should be established to ensure future leaders are adequately prepared for the HBCU environment. Using models such as the ACE Spectrum program, formal mentoring programs should be geared toward equipping those aspiring to the HBCU presidency with a unique skill set that is needed for the HBCU sector. These skill sets would include, but not be limited to, servant leadership, fundraising and development, navigating institutional culture, board relations, public relations, fortifying federal and state government relations, collecting data and making data-driven decisions, strategic planning, and implementing and executing shared governance. These formal programs would work best in multi-year, cohort models. The programs would also need to include opportunities for program participants to have substantial conversations and relationships with current HBCU presidents. In order for these ventures to be successful, foundations and funders that have a vested interest in HBCUs, diversifying the academic workforce, and strengthening the presidential pipeline should offer support for researchers and institutions that attempt to create these formal programs. In addition to establishing and fortifying the mentoring opportunities for future HBCU leaders, future HBCU leaders should seize every opportunity to learn more about the institutional structure and governance at HBCUs and strengthen their soft skills. HBCU leaders who avail themselves to provide mentoring and advice prove essential to ensuring the next generation of HBCU leaders is equipped to take the helm.

Author Contributions: Felecia Commodore conducted the literature review, the first analysis of the data, and wrote the first draft of the paper. All four authors contributed to the writing, research, and analysis of this paper. More specifically, Sydney Freeman, Felecia Commodore, and Courtney Carter conducted the interviews, assisted with the literature review, and edited the paper. Marybeth Gasman reviewed, contributed writing, edited, conducted a second round of analysis, provided the recommendations and served as the corresponding author.

Conflicts of Interest: The authors declare no conflict of interest.

\section{References}

1. Umpstead, R.; Hoffman, H.; Pehrsson, D.E. Building leadership from within the ranks: Leadership fellow initiative. Adv. Women Leadersh. 2015, 35, 144-152.

2. Freeman, S.; Kochan, F.K. Academic pathways to university leadership: Presidents' descriptions of their doctoral education. Int. J. Dr. Stud. 2012, 7, 93-124.

3. Reille, A.; Kezar, A. Balancing the pros and cons of community college "Grow-Your-Own" leadership programs. Community Coll. Rev. 2010, 38, 59-81. [CrossRef]

4. Chang, H.; Longman, K.A.; Franco, M.A. Leadership development through mentoring in higher education: A collaborative autoethnography of leaders of color. Mentor. Tutor. Partnersh. Learn. 2014, 22, 373-389. [CrossRef]

5. Freeman, S.; Gasman, M. The characteristics of historically black college and university presidents and their role in grooming the next generation of leaders. Teach. Coll. Rec. 2014, 116, 1-34.

6. Ricard, R.B.; Brown, M.C. Ebony Towers in Higher Education: The Evolution, Mission, and Presidency of Historically Black Colleges and Universities; Stylus: Sterling, VA, USA, 2008.

7. Gasman, M. "Salvaging academic disaster areas": The black college response to Christopher Jencks' and David Reisman's 1967 Harvard educational review article. J. High. Educ. 2006, 77, 318-352. [CrossRef]

8. Minor, J.T. Decision making in historically black colleges and universities: Defining the governance context. J. Negro Educ. 2004, 73, 40-52. [CrossRef]

9. Minor, J.T. Discerning facts about faculty governance at HBCUs. Academe 2005, 91, 34-38. [CrossRef] 
10. Cook, B.J. The American College President Study: Key Findings and Takeaways. The Presidency (Spring Supplement). 2012. Available online: http://www.acenet.edu/the-presidency/columns-and-features/ Pages/The-American-College-President-Study.aspx (accessed on 8 June 2015).

11. Herring, P.M. Historically Black College and University Presidents: Personal and Professional Challenges, Career Paths, and Leadership Characteristics. Master's Thesis, Fayetteville State University, Fayetteville, NC, USA, 2010.

12. Holmes, S.L. An overview of African American college presidents: A game of two steps forward, one step backward, and standing still. J. Negro Educ. 2004, 73, 21-39. [CrossRef]

13. American Council on Education. The American Presidency; American Council on Education: Washington, DC, USA, 2012.

14. Bozeman, B.; Feeney, M. Toward a useful theory of mentoring. Adm. Soc. 2007, 39, 719-739. [CrossRef]

15. Zach, L. Using a multiple-case studies design to investigate the information-seeking behavior of arts administrators. Lib. Trends 2006, 55, 4-21. [CrossRef]

16. Miles, M.B.; Huberman, A.M.; Saldaña, J. Qualitative Data Analysis: A Methods Sourcebook; Sage: Los Angeles, CA, USA, 2014.

17. Gasman, M.; Anderson-Thompkins, S. Fund Raising from Black-College Alumni: Successful Strategies for Supporting Alma Mater; Council for Advancement and Support of Education: Washington, DC, USA, 2003.

18. Creswell, J.W. Qualitative Inquiry Research Design: Choosing among Five Approaches; Sage: Los Angeles, CA, USA, 2013.

19. Patton, M.Q. Qualitative Research and Evaluation Methods; Sage: Los Angeles, CA, USA, 2002.

(C) 2016 by the authors; licensee MDPI, Basel, Switzerland. This article is an open access article distributed under the terms and conditions of the Creative Commons Attribution (CC-BY) license (http://creativecommons.org/licenses/by/4.0/). 